Antisocial and Prosocial Behavior in Sport: The Role of Motivational Climate,

Basic Psychological Needs, and Moral Disengagement

Ken Hodge $^{1} \&$ Daniel F. Gucciardi ${ }^{2}$

${ }^{1}$ School of Physical Education, Sport \& Exercise Sciences, University of Otago, New Zealand

${ }^{2}$ School of Physiotherapy \& Exercise Science, Curtin University, Australia

Address all correspondence to:

Ken Hodge, $\mathrm{PhD}$

School of Physical Education, Sport \& Exercise Sciences

University of Otago

PO Box 56

Dunedin

New Zealand

E-mail: $\quad$ ken.hodge@otago.ac.nz

Ph. 64-3-479-8991

FAX 64-3-479-8309

Manuscript accepted for publication in Journal of Sport \& Exercise Psychology: February $17^{\text {th }} 2015$ 


\begin{abstract}
The purpose of this investigation was to examine whether the relationships between contextual factors and basic psychological needs were related to antisocial and prosocial behaviors in sport. A two-study project employing Bayesian path analysis was conducted with competitive athletes (Study 1, $n=291$; Study 2, $n=272$ ). Coach and teammate autonomy-supportive climates had meaningful direct relations with need satisfaction and prosocial behaviors. Coach and teammate controlling climates had meaningful direct relations with antisocial behaviors. Need satisfaction was both directly and indirectly related with both prosocial and antisocial behaviors; while moral disengagement was directly and indirectly related with antisocial behaviors. Overall, these findings reflected substantial evidence from the SDT literature that autonomy-supportive motivational climates are important environmental influences for need satisfaction; and are important correlates of prosocial behavior in sport. Whereas, controlling coach and teammate climates, along with moral disengagement, were important correlates of antisocial behavior in sport.
\end{abstract}

Keywords: autonomy-supportive climate, controlling climate, morality, Bayesian analysis 


\section{Antisocial and Prosocial Behavior in Sport: The Role of Motivational Climate, Basic Psychological Needs, and Moral Disengagement}

"Morality is only moral when it is voluntary."

Lincoln Steffens -- US social commentator (Steffens, 1904/1957)

As the above quote indicates individuals must have the capacity to voluntarily regulate their thoughts, emotions and behavior in line with their moral values if they are to volitionally engage in prosocial behavior and avoid antisocial behavior (Gagné, 2003). Sport has a meaningful role to play, as an important socialization agency, with respect to anti/prosocial behavior. The terms antisocial and prosocial behavior have been used to refer to the inhibitive and proactive aspects of morality (Kavussanu \& Boardley, 2009). Antisocial behaviors are acts intended to harm or disadvantage another individual (Kavussanu \& Boardley 2009), whereas prosocial behaviors have been defined as acts intended to help or benefit another person (Eisenberg \& Fabes, 1998). For example, physically intimidating an opponent and verbally encouraging a teammate are antisocial and prosocial behaviors in sport, respectively.

In recent years researchers have examined self-determination theory (SDT; Deci \& Ryan, 2002) as a motivational framework to explain the psychological underpinnings of antisocial and prosocial variables in sport (e.g., Hodge \& Lonsdale, 2011; Ntoumanis \& Standage, 2009). Ryan and Deci (2000) proposed that motivation can be characterized as existing along a continuum representing two broad types of motivation: autonomous motivation (i.e., intrinsic motivation and self-determined forms of extrinsic motivation), and controlled motivation (i.e., non-self-determined or controlled extrinsic motivation). Autonomous motivation is dominant when the three basic psychological needs for autonomy, competence and relatedness are satisfied in a particular environment/context; in contrast, controlled motivation is dominant when these basic needs are not satisfied or thwarted (Deci 
\& Ryan, 2000). These three psychological needs are regarded as basic or fundamental to optimal functioning and well-being (Ryan \& Deci, 2000). Feelings of autonomy indicate a perception of choice and an authentic sense of self-direction and volition; competence refers to a feeling that one has the ability and the opportunity to be effective in one's sport, and opportunities to express one's capacities; and relatedness is defined as a sense of mutual caring and connectedness with others (e.g., teammates and coaches). Controlled motivation has been shown to be positively linked to antisocial behaviors/attitudes (e.g., Ntoumanis \& Standage, 2009), whereas autonomous motivation has been shown to be positively associated with prosocial behavior (e.g., Gagné, 2003). However, despite the relevance of autonomous and controlled motivation, the specific role of the three basic psychological needs has not been examined to date with respect to antisocial and prosocial behavior. There is growing evidence in the sport domain (e.g., Adie, Duda, \& Ntoumanis, 2012; Balaguer, González, Fabra, Castillo, Mercé, \& Duda, 2012; Felton \& Jowett, 2013; McDavid, Cox. \& McDonough, 2014) that basic need satisfaction directly influences affect, cognition, and behavior (i.e., not mediated by motivation); consequently, studies investigating this hypothesis with respect to antisocial and prosocial behavior appear warranted.

In this two-study research project we examined direct effects between contextual factors (i.e., coach and teammate autonomy-supportive vs. controlling climates) and basic psychological needs outlined in self-determination theory (SDT; Deci \& Ryan, 2000, 2002; Ryan \& Deci, 2000) with antisocial and prosocial behaviors in sport. We also investigated moral disengagement as a potential mediator of the relationship between basic psychological needs and antisocial behavior (Study 2). Recent research by Hodge and Lonsdale (2011) investigated moral disengagement as a potential mediator of the relationship between controlled/autonomous motivation and antisocial behavior; thus, we extended their research by examining the relations with basic psychological needs. Moral disengagement is the 
selective use of psychosocial manoeuvres that allow an individual to transgress moral standards without experiencing negative affect (e.g., guilt, shame), thereby decreasing constraint on future antisocial behavior (Bandura, 2006). The concept of moral disengagement has recently been examined with respect to antisocial and prosocial behaviors in sport (e.g., Boardley \& Kavussanu, 2008, 2009; Boardley, Grix \& Dewar, 2014; Corrion, Long, Smith, \& d'Arripe-Longueville, 2009).

\section{Basic Psychological Needs and Anti/Prosocial Behavior}

According to Ryan and Deci (2000; Deci \& Ryan, 2000; Weinstein \& Ryan, 2010), the extent to which the three basic needs are satisfied will influence the degree to which an individual engages in positive behaviors (e.g., prosocial behavior), whereas the extent to which these needs are frustrated (or thwarted) will influence the degree to which an individual engages in negative behaviors (e.g., antisocial behavior). Basic Psychological Needs Theory (BPNT) is a sub-theory within SDT (Deci \& Ryan, 2000, 2002), one of the most commonly used models of motivation, optimal growth and psychological well-being employed in psychology. Considerable research has demonstrated that satisfaction of these three basic needs predicts autonomous motivation (Deci \& Ryan, 2002), well-being (Molix \& Nichols, 2013), and other positive outcomes in various life domains such as work, health (Baard, Deci, \& Ryan, 2004), and exercise (Gunnell, Crocker, Wilson, Mack, \& Zumbo, 2013). Ryan and Deci (2000) have argued that humans are naturally inclined to be prosocial animals, given proper nurturing (e.g., an autonomy-supportive environment). When one lacks this nurturing, one is likely to substitute it by pursuing goals (e.g., gain ego enhancement, fame, and extrinsic rewards) that do not promote prosocial behavior (Gagné, 2003). In the few SDT-based studies that have examined moral functioning in sport, it has been shown that autonomously motivated athletes were more likely to report prosocial behaviors/attitudes (Hodge \& Lonsdale, 2011; Ntoumanis \& Standage, 2009), and avoidance of antisocial 
behaviors such as using performance-enhancing drugs (Barkoukis, Lazuras, Tsorbatzoudis \& Rodafinos, 2011); whereas controlled motivation was associated with antisocial behaviors/attitudes (Hodge, Hargreaves, Gerrard, \& Lonsdale, 2013; Ntoumanis \& Standage, 2009). Although the role of autonomous versus controlled motivation has been examined with respect to prosocial/antisocial behavior in sport, the role of basic psychological needs has not been examined relative to these moral variables. Given the importance of basic psychological need satisfaction with respect to autonomous/controlled motivation (Deci \& Ryan, 2000), the influence of autonomous/controlled motivation on prosocial/antisocial behavior (Weinstein \& Ryan, 2010), and the empirical evidence that basic needs explain variance in sport-related variables beyond autonomous/controlled motivation (Adie et al., 2012; Felton \& Jowett, 2013), the direct relations between basic needs and prosocial/antisocial behavior in sport appear to warrant investigation.

There is substantial evidence regarding the role of need satisfaction in sport, with studies indicating that autonomy, competence, and relatedness scores predict levels of autonomous motivation (Ntoumanis \& Standage, 2009), sport continuation (Gucciardi \& Jackson, 2015), well-being (Felton \& Jowett, 2013), subjective vitality (Balaguer et al., 2012), athlete burnout (Li, Wang, Pyun, \& Kee, 2013), mental toughness (Mahoney, Gucciardi, Ntoumanis, \& Mallett, 2014), and performance in sport (Sheldon, Zhaoyang, \& Williams, 2013). Given the theoretical and empirical links amongst need satisfaction, positive consequences (e.g., well-being), and negative consequences (e.g., burnout) in sport, it was expected that the satisfaction of autonomy, competence and relatedness needs would predict positive relations with prosocial behavior, and negative relations with antisocial behavior in sport.

\section{Contextual Determinants of Anti/Prosocial Behavior in Sport}


Research employing an SDT perspective has demonstrated the importance of considering contextual (autonomy-supportive and controlling motivational climates) as well as person (basic needs; autonomous and controlled motivation) variables with respect to antisocial and prosocial variables in sport (e.g., Hodge et al., 2013; Ntoumanis \& Standage, 2009). From a BPNT standpoint, the influence of autonomy-supportive versus controlling motivational climates is viewed as a fundamental environmental influence for the satisfaction of the three basic needs (Adie et al., 2012; Moreau, \& Mageau, 2012). Motivational climate refers to the goals and behaviors emphasized, and the values that are salient, in the social environment created by significant others (e.g., coaches, teammates, peers; Baard, et al., 2004). A number of authors have contended that the coach is one of the most influential individuals in the athlete's sport experience and the contextual environment the coach creates amongst his/her team/training squad (e.g., Bartholomew, Ntoumanis, \& ThøgersenNtoumani, 2010; Gagné, Ryan, \& Bargmann, 2003; Rutten, Schuengel, Dirks, Stams, Biesta, \& Hoeksma, 2011). Teammates and training partners can also influence the creation of an autonomy-supportive versus a controlling climate through means similar to those of the coach (Hodge et al., 2013; Kipp \& Weiss, 2013). Consequently, it is important to identify the relevance of teammate-driven as well as coach-driven climates with respect to need satisfaction (see also Jõesaar, Hein \& Hagger, 2011; Moreau \& Mageau, 2012; Ntoumanis, Taylor, \& Thøgersen-Ntoumani, 2012).

In a controlling environment, coaches and teammates may behave in a coercive, pressuring, and authoritarian way, and employ strategies such as manipulation, obedience, guilt induction, controlling competence feedback, and conditional regard to impose a specific and preconceived way of thinking and behaving upon their athletes/teammates (Bartholomew et al., 2010). In contrast, in an autonomy-supportive environment athletes are provided with choice and a rationale for tasks, their feelings are acknowledged, opportunities to show 
initiative and independent work are provided, athletes are given non-controlling competence feedback, and overt control is avoided (Gagné et al., 2003; Kipp \& Weiss, 2013).

Control, whether by external forces or by oneself, entails regulatory processes that are more rigid, involve greater pressure, tension and a more negative emotional tone, and result in less integrated motivation (Deci \& Ryan, 2002) as well as potential antisocial behavior. On the other hand, researchers have argued that autonomous motivation is a central determinant of prosocial behavior (e.g., Gagné, 2003) - the assumption in the present research was that motivation for prosocial behavior would be enriched by autonomy-supportive climates and dampened by controlling climates, because these factors affect the satisfaction of basic psychological needs. Thus, as Gagné (2003) asserted, autonomy-support should orient people toward paying more attention to others, and therefore more likely to engage in prosocial behavior and less likely to engage in antisocial behavior (Rutten et al., 2011). In contrast, controlling climates should orient people toward paying less attention to others, and therefore more likely to engage in antisocial behavior and less likely to engage in prosocial behavior (Hodge et al., 2013).

Contextual variables and the social environment also play an important role in determining moral thought and action (Bandura, 2002, 2006; Long, Pantaléon, Bruant, \& d'Arripe-Longueville, 2006; Ntoumanis et al., 2012; Rutten et al., 2011). Athletes who perceive controlling climates may morally disengage by displacing responsibility for their actions on their coach/teammates (e.g., it's not my fault), by blaming the people they harm in response to provocation (e.g., he/she deserved it), or by justifying antisocial behaviors as a legitimate means to a desired end emphasized by the coach and teammates (e.g., to help my team win). Moral disengagement, therefore, may mediate the relations between controlling climates, basic need satisfaction, and antisocial behaviors.

\section{Moral Disengagement}


Bandura $(2002,2006)$ suggested that in the development of moral agency, individuals engage in a self-regulatory process in which they adopt standards of right and wrong that serve as guides for their conduct. Individuals monitor their conduct and the conditions under which it occurs, judge it in relation to their moral standards and perceived circumstances, and regulate their actions by the consequences they apply to themselves. According to Bandura (2006), transgressive conduct is regulated by two major sources of sanctions, social sanctions and internalized self-sanctions, that operate anticipatorily. With social sanctions, individuals refrain from transgressing because they fear that such conduct will bring them social censure. Whereas with internalized self-sanctions, individuals behave prosocially because it produces self-satisfaction and self-respect and they refrain from antisocial behavior because such actions would provoke self-censure and self-reproof (Bandura, 2006).

Known collectively as the 'mechanisms of moral disengagement', Bandura (2002, 2006) argued that the use of eight psychological manoeuvres allows individuals to transgress moral standards without experiencing negative affect (e.g., self-censure, guilt), thereby decreasing constraint on future negative behavior. The eight mechanisms of moral disengagement are: moral justification, euphemistic labeling, advantageous comparison, displacement of responsibility, dehumanization, attribution of blame, distortion of consequences, and diffusion of responsibility. These eight mechanisms are explained by Bandura (2002), and Boardley and Kavussanu (2011) have offered sport examples for each mechanism. Moral disengagement has been associated with antisocial behaviors in sport (e.g., Boardley et al., 2014; Corrion et al, 2009; Hodge et al., 2013; Stanger, Kavussanu, Boardley, \& Ring, 2013), and inversely linked to prosocial behavior in team sports (Boardley \& Kavussanu, 2009).

\section{Purpose and Hypotheses}


The purpose of this two-study research project was to examine both direct and indirect (mediator) relations amongst contextual factors (i.e., autonomy-supportive vs. controlling climates), basic psychological needs, moral disengagement, and antisocial and prosocial behaviors in sport. In these studies we extended previous SDT research on antisocial and prosocial behavior in sport by (i) integrating basic psychological needs variables with prosocial behaviors (Study 1), (ii) integrating basic psychological needs variables with both prosocial and antisocial behaviors, and with moral disengagement (Study 2), (iii) assessing controlling as well as autonomy-supportive climates (Study 2), and (iv) assessing teammate as well as coach autonomy-supportive and controlling climates (Study 2).

Study 1. We hypothesized that an autonomy-supportive coach climate would have a positive direct effect with prosocial behaviors toward both teammates and opponents, and that those effects would be mediated by basic psychological need satisfaction. We tested the following specific hypotheses in Study 1 (see Figure 1).

H1a: autonomy support from the coach will have a positive direct effect with need satisfaction.

H1b: autonomy support from the coach will have a positive direct effect with prosocial behaviors toward both teammates and opponents.

H1c: need satisfaction will have a positive direct effect with prosocial behaviors toward both teammates and opponents.

H1d: the direct effect from autonomy support from the coach to prosocial behaviors will be mediated by need satisfaction.

Study 2. We extended upon Study 1 to include antisocial behaviors, and we examined moral disengagement as a potential mediator variable. Previous research by Hodge and Lonsdale (2011) had investigated the role of moral disengagement with autonomous/controlled motivation, but not with basic needs. In addition, we extended our 
contextual environment focus to include controlling as well as autonomy-supportive climates, and in doing so we also assessed teammate as well as coach climates. As with Study 1, we hypothesized that an autonomy-supportive climate (coach and teammate) would have a positive direct effect with prosocial behaviors toward both teammates and opponents, and those effects would be mediated by need satisfaction. We also hypothesized that controlling climates (coach and teammate) would have a positive direct effect with antisocial behaviors toward both teammates and opponents, and those effects would be mediated by need satisfaction and moral disengagement. We tested the following specific hypotheses in Study 2 (see Figure 2).

H2a: autonomy support (from coach and teammates) will have a positive direct effect with need satisfaction.

$\mathrm{H} 2 \mathrm{~b}$ : autonomy support (from coach and teammates) will have a positive direct effect with prosocial behaviors toward both teammates and opponents.

H2c: need satisfaction will have a positive direct effect with prosocial behaviors toward both teammates and opponents.

$\mathrm{H} 2 \mathrm{~d}$ : the direct effect from autonomy support (from coach and teammates) to prosocial behaviors would be mediated by need satisfaction.

H2e: controlling climates (from coach and teammates) will have an inverse direct effect with need satisfaction.

H2f: controlling climates (from coach and teammates) will have a positive direct effect with antisocial behaviors toward both teammates and opponents.

$\mathrm{H} 2 \mathrm{~g}$ : need satisfaction will have an inverse direct effect with antisocial behaviors toward both teammates and opponents.

H2h: the direct effects between controlling climates (from coach and teammates) and antisocial behaviors will be mediated by need satisfaction. 
H2i: the direct effects between controlling climates (from coach and teammates) and antisocial behaviors will be mediated by moral disengagement.

\section{Study 1: Method}

\section{Study 1: Participants and Procedures}

Participants were 291 competitive athletes from a [name deleted for blind review] university $(60 \%$ female; mean age $=19.52 \mathrm{yrs}, S D=1.69 \mathrm{yrs})$, from both individual $(n=79)$ and team $(n=211)$ sports. The sample included experienced $(M=9.85$ yrs participating in their sport; $S D=3.85 \mathrm{yrs})$ club level athletes $(n=77)$, provincial age-grade representatives $(n$ $=132)$, national age-group representatives $(n=38)$, provincial senior representatives $(n=28)$ and national senior representatives $(n=18)$. Ethical approval was received from the first author's university ethics committee and informed consent was received from all participants. These data were collected as part of a wider project examining SDT variables in sport (citation deleted for blind review).

\section{Study 1: Measures}

Autonomy-supportive coaching climate. This questionnaire assessed athletes' perceptions of autonomy-supportive behaviors exhibited by the coach in their major sport. We adapted 14 items from the Health Care Climate Questionnaire (Williams, Cox, Kouides, \& Deci, 1999) to assess autonomy-supportive coaching style (e.g., "I feel that my coach cares about me as a person”). Participants responded to each item using a 7-point Likert scale (1 = "Strongly disagree", 7 = "Strongly agree"). Past work in sport has documented support for the psychometric properties of adapted versions of this autonomy-supportive scale (Ntoumanis \& Standage, 2009).

Psychological need satisfaction. The basic psychological needs for autonomy, competence and relatedness were assessed using the Basic Need Satisfaction in Sport Scale (Ng, Lonsdale \& Hodge, 2011). The competence and relatedness subscales contained five 
items each. Autonomy consisted of three interrelated subscales, namely, internal locus of causality (IPLOC; 3 items), perceived choice (4 items), and volition (3 items). Example items included "I feel I am good at my sport" (competence), "I have close relationships with people in my sport" (relatedness), "In my sport, I get opportunities to make decisions" (autonomy choice), "In my sport, I feel I am pursuing goals that are my own" (autonomy - IPLOC), and "I choose to participate in my sport according to my own free will" (autonomy - volition). For the purpose of the current research a global autonomy score was utilized in data analysis (i.e., mean of the three autonomy subscale scores; $\mathrm{Ng}$ et al., 2011). Questions were answered on a 7-point Likert scale ( $1=$ "Not true at all", $7=$ "Very true"). Initial research has supported the reliability and validity of the BNSSS (Ng et al., 2011).

Prosocial and antisocial behavior in sport scale (PABSS). Athletes were asked to indicate how often they had engaged in prosocial and antisocial behaviors during the current competitive season or their most recent season. Participants answered each item using a 5point Likert scale ( $1=$ "Never", 5 = "Very often"). The 20-item PABSS (Kavussanu \& Boardley, 2009; Kavussanu, Stanger, \& Boardley, 2013) consists of four subscales; (i) prosocial behavior towards teammates (four items; e.g. "congratulated a teammate/training partner"), (ii) prosocial behavior towards opponents (three items; e.g. "helped an injured opponent"), (iii) antisocial behavior towards teammates (five items; e.g., "verbally abused a teammate/training partner"), and (iv) antisocial behavior towards opponents (eight items; e.g. "physically intimidated an opponent"). Kavussanu and colleagues (2009, 2013) have provided evidence for the validity and reliability of the four subscales' scores with team sport athletes. We adapted/re-worded the 'teammate' items to include behaviors in individual sports as well (e.g., "Gave positive feedback to a teammate/training partner"). Hodge and Lonsdale (2011) reported acceptable psychometric properties for the validity and reliability of the teammate/training partner adaptation of the PABSS. 


\section{Study 1: Data analysis}

We first examined descriptive statistics and the internal consistency of subscale scores ( $\alpha$ coefficients) for all study variables. We subsequently tested the hypothesized theoretical sequence depicted in Figure 1 using Bayesian path analysis (Muthén \& Asparouhov, 2012) in Mplus 7.1 (Muthén \& Muthén, 1998-2012). Bayesian estimation was preferred instead of the traditional maximum-likelihood (ML) approach for both methodological and substantive reasons. From a methodological standpoint, Bayesian analysis produces better small-sample performance including more accurate parameter estimates and confidence (or credibility) intervals (van de Schoot et al., 2014; Zyphur \& Oswald, 2015). Substantively, Bayesian estimation allows one to integrate prior knowledge with new data via statistical analyses, thereby "yielding results that are automatic meta-analyses" (Zyphur \& Oswald, 2015, p. 2). This existing or background knowledge can be formed based on pilot data, expert knowledge, theoretical expectations, or meta-analyses (van de Schoot et al., 2014; Zyphur \& Oswald, 2015). The Bayesian approach contrasts with frequentist methods in which the null hypothesis is repeatedly tested, even in those instances in which previous research provides evidence to guide expectations regarding the nature of one's data (van de Schoot et al., 2014). Both direct and indirect effects were of interest in our main analysis; interested readers should consult Yuan and MacKinnon (2009) for an excellent overview of Bayesian mediation analysis. Missing data were handled using the full-information maximum likelihood estimation method to enable the use of all available data. Nevertheless, we also report the results of a frequentist analysis using a robust maximum likelihood estimator (MLR) for those readers who may be interested to know how these results compare with the Bayesian findings.

An overview of the priors employed for the Bayesian path analysis is detailed in Table 1; interested readers can obtain a copy of the Mplus syntax from the second author. 
Informative priors based on previous empirical research were employed to specify a distribution of the pathways between autonomy support with need satisfaction (Adie et al., 2012) and prosocial behavior (Hodge \& Lonsdale, 2011). In contrast, theoretical expectations informed our priors regarding the direct effects between need satisfaction and prosocial behavior owing to the limited prior knowledge on these effects. Specifically, informative priors were modeled such that need satisfaction were expected to evidence a positive relation with prosocial behavior $\left(\mu=.40 ; \sigma^{2}=.04\right)$. Noninformative priors were employed for residual variances and covariances among exogenous and endogenous variables. We employed a convergence criterion of .01 (van de Schoot et al., 2015) and a minimum of 30,000 iterations each for two independent chains of the Markov chain Monte Carlo (MCMC) to generate the posterior distribution based on the parameter specifications and observed data (Muthén \& Asparouhov, 2012). Credibility intervals (CI), which reflect a 95\% probability that the true value of a parameter occurs between two boundaries, provided an insight into the precision of parameter estimates; a parameter is considered significantly different from zero when the credibility interval does not encompass zero (Muthén \& Asparouhov, 2012). The posterior predictive $p$-value (PPP) is the probability that the replicated data may be more extreme than the observed data, and therefore provides an indication of the adequacy of a Bayesian model (Muthén \& Asparouhov, 2012). Small PPP values (e.g., .005) are indicative of poor fit, whereas values around .50 indicate a good fit. Model convergence was assessed with the potential scale reduction factor (PSR; <1.01) and visual inspection of the trace plots (i.e., multiple chains with similar target distributions) (Asparouhov \& Muthén, 2010; Gelman, Meng, \& Stern, 1996).

\section{Study 1: Results}

Descriptive statistics, internal reliability estimates, and zero-order correlations among study variables are detailed in Table 2. All measures evidenced adequate levels of internal 
reliability ( $\geq .70 ;$ Nunnally \& Bernstein, 1994). The probability of the hypothesized theoretical model was excellent $\left(\mathrm{PPP}=.490, \Delta\right.$ observed and replicated $\chi^{2} 95 \%$ CI $[-20.34$, 21.16]). Model convergence was reached after 10800 iterations (PSR < 1.01) and subsequently verified through visual inspection of trace plots. An overview of the results with regard to direct effects is detailed in Table 4. Specifically, perceived autonomy support from the coach evidenced a positive direct effect with all three psychological needs; in turn, the satisfaction of relatedness and competence had a positive direct effect on prosocial behavior toward one's teammates. Autonomy support accounted for a meaningful amount of variance in the psychological needs of relatedness (16\%), competence (13\%) and autonomy (31\%); need satisfaction explained $19 \%$ and $4 \%$ of the variance in prosocial behavior towards one's teammates and opponents, respectively. Alongside these direct effects, two indirect pathways were found to be of a magnitude that is important with Bayesian estimation. Perceived autonomy support influenced prosocial behavior towards teammates via satisfaction of relatedness (unstandardized estimate $=.06,95 \% \mathrm{CI}[.03, .09]$ ) and competence needs (unstandardized estimate $=.03,95 \%$ CI $[.01,06]$ ). These Bayesian indirect effects were corroborated with MLR estimation both in terms of magnitude and direction, as well as their statistical relevance (i.e., confidence intervals did not encompass zero).

\section{Study 2: Method}

\section{Study 2: Participants and Procedures}

Participants were 272 team sport athletes from a [name deleted for blind review] university $(60 \%$ female; mean age $=19.49 \mathrm{yrs}, S D=1.54 \mathrm{yrs})$. The sample included experienced $(M=9.90 \mathrm{yrs}$ participating in their sport; $S D=3.86 \mathrm{yrs})$ club level athletes $(n=$ 78), provincial age-grade representatives $(n=106)$, national age-group representatives $(n=$ 36), provincial senior representatives $(n=38)$ and national senior representatives $(n=14)$. Ethical approval was received from the first author's university ethics committee and 
informed consent was received from all participants. These data were collected as part of a wider project examining SDT variables and doping in sport (citation deleted for blind review).

\section{Study 2: Measures}

Autonomy-supportive coach/teammate climate. We assessed athletes' perceptions of autonomy-supportive behaviors exhibited by the coach in their major sport. See Study 1 for a description of the coach measure. We also employed a modified version of this questionnaire to assess athletes' perceptions of autonomy-supportive styles exhibited by teammates/training partners. Participants responded to the following stem: "This questionnaire contains items that are related to your experience with your teammates/training partners. Teams (training squads) have different interaction styles, and we would like to know more about how you have felt about your encounters with your teammates/training partners."

Controlling coach/teammate climate. We used the Coach Controlling Behaviors Scale (CCBS; Bartholomew et al., 2010) to assess the controlling dimension of coaching style/climate. The CCBS is a 15-item questionnaire, answers are given on a 7-point Likert scale $(1=$ Strongly disagree, $7=$ Strongly agree $)$. There are four subscales of controlling interpersonal styles that have been identified; controlling use of rewards (e.g. "My coach only rewards/praises me to make me train harder"; 4 items), negative conditional regard (e.g. "My coach is less supportive of me when I am not training and competing well"; 4 items), intimidation (e.g. "My coach shouts at me in front of others to make me do certain things"; 4 items) and excessive personal control (e.g. "My coach tries to control what I do during my free time"; 3 items). Initial research indicated good psychometric properties for the four factor model of the CCBS, as well as an overall score for coach controlling climate (see Bartholomew et al., 2010). We also used a modified version of the CCBS to assess the controlling aspects of teammate/training partner climate. 
Psychological need satisfaction. See Study 1 for a description of this measure.

Moral disengagement in sport scale-short (MDSS-S). The short form of the MDSS (Boardley \& Kavussanu, 2008) was employed to measure athletes' overall sport moral disengagement. Participants responded to eight items (e.g., "A player should not be blamed for injuring an opponent if the coach reinforces such behavior"; "Bending the rules is a way of evening things up"), each item representing one of the eight psychological mechanisms for moral disengagement (Bandura, 2006), by indicating how much they agreed with each statement (using a 7-point Likert scale; 1 = "Strongly disagree", 7 = "Strongly agree"). Satisfactory psychometric properties for the short form of the MDSS have been reported by Boardley and Kavussanu (2008, 2009) and Stanger et al. (2013).

Prosocial and antisocial behavior in sport scale (PABSS). See Study 1 for a description of this measure.

\section{Study 2: Data analysis}

We analyzed the theoretical model depicted in Figure 2 using the same approach as Study 1. An overview of the priors employed for the Bayesian path analysis is detailed in Table 1. Empirical evidence obtained in Study 1 was employed to inform priors of direct effects in the theoretical sequence of Study 2, which were replicated in this new dataset. These direct effects included coach autonomy support as a predictor of need satisfaction, coach autonomy support as a predictor of prosocial behavior, and need satisfaction as a predictor of prosocial behavior. Informative priors based on previous research were employed to specify a distribution of the relations between controlling coach behaviors and need satisfaction (Balaguer et al., 2012; Felton \& Jowett, 2013). Theoretical expectations informed our expectations regarding all other relations (e.g., teammate autonomy support predicts need satisfaction).

\section{Study 2: Results}


Descriptive statistics, internal reliability estimates, and zero-order correlations among study variables are reported in Table 3. All measures evidenced adequate levels of internal reliability. The probability of the hypothesized theoretical model was excellent $(\mathrm{PPP}=.479$, $\Delta$ observed and replicated $\chi^{2} 95 \%$ CI $\left.[-38.76,38.67]\right)$. Model convergence was reached after 17900 iterations (PSR < 1.01) and subsequently verified through visual inspection of trace plots. An overview of the results with regard to direct relations is detailed in Table 4. Here we report the Bayesian results; readers can consult Table 4 for MLR estimation results. Perceived autonomy support from the coach and one's teammates had positive direct effects with all three psychological needs, whereas controlling climates (coach and teammate) did not evidence significant direct effects with the three basic needs. The perception that coaches and teammates were controlling had a positive direct effect with moral disengagement, whereas moral disengagement and perceived controlling teammates predicted higher levels of antisocial behaviour towards opponents and teammates. In contrast, there was an inverse direct effect from perceived teammate autonomy support to antisocial behavior toward one's teammates. Perceived satisfaction of the psychological needs for relatedness and competence had a positive direct effect with prosocial behavior towards one's teammates, whereas only relatedness perceptions were predicted higher levels of prosocial behavior towards one's opponents. Finally, moral disengagement and satisfaction levels of the need for relatedness predicted higher levels of prosocial behavior towards one's opponents. Coach and teammate climates accounted for a meaningful amount of variance in moral disengagement (14\%), and the satisfaction of the three psychological needs for relatedness $(38 \%)$, competence $(15 \%)$ and autonomy (28\%). Moral disengagement, coach and teammate climates, and psychological needs satisfaction explained an important amount of variance in prosocial behavior towards one's teammates $(26 \%)$ and opponents $(11 \%)$, and antisocial behavior towards one's teammates (42\%) and opponents (48\%). 
Alongside these direct relations, several indirect pathways were found to be of a magnitude that is important. Moral disengagement accounted for a significant proportion of the relation between controlling coach climates with prosocial behavior towards opponents (unstandardized estimate $=-.03,95 \%$ CI $[-.07,-.01]$ ), and antisocial behavior towards teammates (unstandardized estimate $=.07,95 \%$ CI $[.02, .12]$ ) and opponents (unstandardized estimate $=.10,95 \% \mathrm{CI}[.03, .17])$. Additionally, moral disengagement emerged as a mediator of the relations between controlling teammate climate and prosocial behavior towards opponents (unstandardized estimate $=-.03,95 \%$ CI $[-.06,-.01]$ ), and antisocial behavior towards teammates (unstandardized estimate $=.06,95 \%$ CI $[.01, .12]$ ) and opponents (unstandardized estimate $=.09,95 \%$ CI $[.02, .16]$ ). Perceived autonomy support from coaches influenced prosocial behavior towards teammates via satisfaction of relatedness (unstandardized estimate $=.04,95 \%$ CI $[.02, .06]$ ) and competence needs (unstandardized estimate $=.02,95 \% \mathrm{CI}[.01,05])$; and prosocial behavior towards opponents via relatedness (unstandardized estimate $=.04,95 \%$ CI $[.01, .08]$ ). Similar findings emerged for autonomy support from teammates, such that the direct effect between these teammate behaviors and prosocial behavior towards teammates was mediated via satisfaction of relatedness (unstandardized estimate $=.07,95 \%$ CI $[.04, .11]$ ) and competence needs (unstandardized estimate $=.01,95 \% \mathrm{CI}[.001,03])$; and prosocial behavior towards opponents via relatedness (unstandardized estimate $=.09,95 \%$ CI $[.02, .15]$ ). These Bayesian indirect effects were corroborated with MLR estimation both in terms of magnitude and direction; however, differences emerged with regard to the statistical relevance of these effects. Specifically, five of the 12 meaningful indirect effects reported above for the Bayesian analysis were not statistically significant with MLR estimation, namely: controlling coach climate $\rightarrow$ moral disengagement $\rightarrow$ prosocial behaviors towards opponents, controlling coach climate $\rightarrow$ moral disengagement $\rightarrow$ antisocial behaviors towards teammates, controlling teammate climate $\rightarrow$ 
moral disengagement $\rightarrow$ prosocial behaviors towards opponents, controlling teammate climate $\rightarrow$ moral disengagement $\rightarrow$ antisocial behaviors towards teammates, and controlling teammate climate $\rightarrow$ moral disengagement $\rightarrow$ antisocial behaviors towards opponents. The MLR findings appear to be related to the reduction of precision in the estimation of the confidence intervals of these indirect effects; further information on the advantages of Bayesian mediation analysis are described by Yuan and McKinnon (2009).

\section{General Discussion}

The purpose of this two-study project was to examine relationships amongst contextual factors, basic psychological needs, and moral disengagement with antisocial and prosocial behaviors in sport. We investigated both the direct and indirect (mediator) effects of psychological need satisfaction on antisocial and prosocial behaviors. We also examined moral disengagement as a potential mediator of the direct effects between the motivational climate and antisocial behaviors. In general, our BPNT and SDT hypotheses were supported. These athletes reported high scores on their perceptions of coach autonomy-support (both studies) and teammate autonomy-support (Study 2), basic need satisfaction (both studies), and prosocial behavior towards both teammates and opponents (although opponents scores were moderate-high in both studies). These high scores were consistent with recent research in sport (e.g., Adie et al., 2013; Gunnell et al., 2013; Kavussanu \& Boardley, 2009; Kipp \& Weiss, 2013). Study 2 revealed overall low scores on perceived coach and teammate controlling climates, moral disengagement, and antisocial behavior; which was also consistent with recent research in sport (e.g., Bartholomew et al., 2010, 2011; Boardley \& Kavussanu, 2007, 2009; Kavussanu \& Boardley, 2009; Stanger et al., 2013). These SDT findings were positive given the evidence supporting adaptive psychological outcomes (e.g., subjective well-being, enjoyment, work/life satisfaction, less stress) stemming from autonomy-supportive climates and basic need satisfaction (Moreau \& Mageau, 2012; Ryan \& 
Deci, 2000). Levels of moral disengagement and antisocial behavior towards both teammates and opponents were low (Study 2), which was heartening given the negative outcomes (e.g., aggressive behavior, cheating, doping) associated with these personal characteristics (Bandura, 2006; Boardley \& Kavussanu, 2011; Corrion et al., 2009).

\section{Contextual Climates and Psychological Needs}

Our results indicated that perceived autonomy-supportive climates from both coaches (Studies 1 and 2) and teammates (Study 2) had a direct positive relation with all three basic needs. These findings supported hypotheses H1a and H2a. On the other hand, perceived controlling climates (coach and teammates) were not of a magnitude that was important (negatively) for the prediction of basic need satisfaction in Study 2; this finding refuted hypothesis H2e. In general, these findings reflected substantial evidence from the BPNT and SDT literatures (across multiple life domains) that autonomy-supportive versus controlling motivational climates are critical environmental influences for the satisfaction of the three basic needs (e.g., Adie et al., 2012; Gagné, et al., 2003; Moreau, \& Mageau, 2012). Moreover, our results also supported the importance of 'peer' (i.e., teammates, friends, coworkers) autonomy-supportive climates in addition to coach climates with respect to need satisfaction (Jõesaar et al., 2011; Moreau \& Mageau, 2012). Autonomy-supportive climates have been shown to predict need satisfaction in sport (e.g., Balaguer et al., 2012; Bartholomew, Ntoumanis, Ryan, Bosch, \& Thøgersen-Ntoumani, 2011), with autonomysupportive coaches more likely to consider the athlete's perspective, offer a rationale for coaching decisions, and promote choice and decision-making for their athletes. It is assumed in BPNT that such interpersonal behaviors will lead to greater need satisfaction -- our results supported this assumption, but also highlighted the importance of autonomy-supportive teammate climates with respect to need satisfaction.

\section{Contextual Climates and Anti/Prosocial Behavior}


As hypothesized perceived autonomy-supportive climates showed a direct positive relation with prosocial behavior toward teammates in both studies $(\mathrm{H} 1 \mathrm{~b} ; \mathrm{H} 2 \mathrm{~b})$; Study 2 results indicated that both coach and teammate autonomy-supportive climates predicted prosocial behavior towards both teammates and opponents. These direct effects were partially mediated by need satisfaction $(\mathrm{H} 1 \mathrm{~d} ; \mathrm{H} 2 \mathrm{~d})$, but only with respect to prosocial behavior towards teammates (both studies), and two of the basic needs (i.e., relatedness, competence). The latter finding indicated a differential relationship between autonomy-supportive climates, basic needs, and teammate versus opponent-focused prosocial behaviors. Perhaps the athletes in our two studies were more inclined to act in a prosocial manner towards people with whom they had a personal relationship (i.e., teammates) as opposed to those with whom they had an impersonal relationship (i.e., opponents). Nevertheless, as suggested by Hodge and Lonsdale (2011) the items used to measure prosocial and antisocial behaviors toward teammates and opponents may have influenced these results. Prosocial and antisocial opponent behaviors, as measured by the PABSS, were both verbal and physical, whereas teammate behaviors were only verbal. Consequently, it was not possible to determine if motivational climates were differentially predictive of behaviors toward teammates versus opponents, or the type of behavior assessed (i.e., verbal vs. physical).

Our Study 2 findings indicated that the perception of controlling climates from teammates, but not coaches, had a direct positive relation with self-reported antisocial behavior towards both teammates and opponents (H2f). Controlling climates reflect influences based upon coercive demands and reward contingencies (i.e., external regulation), and/or an athlete's sense of guilt or obligation (i.e., introjected regulation). Such pressures force athletes into engaging in requested behaviors (e.g., antisocial behaviors) that are carried out, but likely do not reflect personal endorsement on the athlete's behalf (Bartholomew et al., 2010). The relationships between controlling climates and antisocial behaviors were 
mediated by need satisfaction (hypothesis $\mathrm{H} 2 \mathrm{~h}$ ), which was consistent with the BPNT and SDT literatures (e.g., Felton \& Jowett, 2013; Gagné, 2003; Ntoumanis \& Standage, 2009). Study 2 also revealed a mediating effect for relatedness and prosocial behavior towards opponents (for both coach and teammate climates). Given that the basic need for relatedness has previously been regarded as less important than the other needs (Deci \& Ryan, 2000), our finding that relatedness was an important mediator in the relationship between motivational climate and prosocial behavior was notable. Indeed, this finding supported recent research indicating that relatedness predicts prosocial behavior (i.e., volunteering and charitable donations; Pavey, Greitemeyer, \& Sparks, 2011), and that sport is a context in which relatedness emerges as a significant predictor of well-being over time (Adie et al., 2012; Gunnell et al., 2013). Since relatedness focuses on caring about others (and being cared for oneself), this basic need should logically have a strong relationship with prosocial behaviors which are characterized by an altruistic concern for the welfare of others. Consequently future research should investigate not whether relatedness is important in sport, but under what circumstances it is important.

\section{Psychological Needs and Prosocial Behavior}

Results from both studies indicated that basic need satisfaction had a direct positive relationship with self-reported prosocial behavior (towards teammates only), but only two of the basic needs (i.e., relatedness, competence) were found to be of a magnitude that is important. Alongside these direct relations, the basic needs of relatedness and competence partially mediated the relationship between autonomy support and prosocial behavior towards teammates (Study 1). Similar findings were found in Study 2, with the basic needs of relatedness and competence partially mediating the relationship between autonomy support and prosocial behavior towards teammates (but not opponents). These findings provided partial support for hypotheses H1c and H2c. As mentioned earlier, Study 2 also revealed a 
positive relationship between the basic need for relatedness and prosocial behavior towards opponents. This relationship appeared to reflect the 'other-focus' aspect of the basic need for relatedness (i.e., caring for others and being cared for, by others; Ryan \& Deci, 2000). Overall, these results were consistent with the BPNT and SDT literatures with respect to need satisfaction and positive psychological outcomes (e.g., Adie et al., 2012; Gagné et al., 2003; Kipp \& Weiss, 2013; McDavid et al., 2014; Molix \& Nichols, 2013; Pavey et al., 2011). Nevertheless, the absence of significant effects with the basic need for autonomy was unexpected - given the volitional, self-regulatory nature of moral agency and prosocial behavior (Bandura, 2006) we expected need satisfaction for autonomy to have an important direct effect with prosocial behavior. On the other hand, there is some recent evidence for a lesser role for autonomy in some circumstances (e.g., Pavey et al., 2011); moreover, both Adie et al. (2012) and Gunnell at al. (2013) found that autonomy was not a significant predictor of well-being in sport.

\section{Contextual Climates, Psychological Needs, Moral Disengagement and Antisocial}

\section{Behavior}

The perception of controlling coach and teammate climates predicted higher levels of moral disengagement, whereas moral disengagement and controlling teammates influenced higher levels of antisocial behavior towards opponents and teammates (Study 2). In contrast, perceived coach autonomy support predicted lower levels of antisocial behavior toward one's teammates. These findings supported previous research in both sport and non-sport environments that has demonstrated the important influence that contextual variables have on moral thought and action (Bandura, 2002, 2006; Long et al., 2006; Ntoumanis et al., 2012; Rutten et al., 2011). As we argued earlier, autonomy-support should orient people toward paying more attention to others, and therefore more likely to engage in prosocial behavior and less likely to engage in antisocial behavior (Gagné, 2003; Rutten et al., 2011). On the 
other hand, controlling climates should orient people toward paying less attention to others, and therefore more likely to engage in antisocial behavior (Hodge et al., 2013) and less likely to engage in prosocial behavior.

Basic need satisfaction had an inverse direct relationship with antisocial behavior towards opponents, but not teammates (Study 2), providing partial support for hypothesis $\mathrm{H} 2 \mathrm{~g}$. These findings were consistent with the BPNT and SDT literatures with respect to inverse relations between need satisfaction and negative psychological outcomes (e.g., Balaguer et al., 2012; Li et al., 2013). Nevertheless, inverse relations between high levels of need satisfaction and antisocial behavior do not address potential positive relations between antisocial behavior and low levels of need satisfaction or with need thwarting. Indeed, low levels of need satisfaction do not necessarily equate to need thwarting. Psychological need thwarting is conceptualized as the perception that need satisfaction is being actively obstructed, impeded, blocked or frustrated in a specific context (Bartholomew, Ntoumanis, Ryan, \& Thøgersen-Ntoumani, 2011). Need thwarting has been associated with negative and maladaptive outcomes in sport (e.g., negative affect, depression, disordered eating, burnout; Bartholomew, Ntoumanis, Ryan, \& Thøgersen-Ntoumani, 2011; Bartholomew, Ntoumanis, Ryan, Bosch, \& Thøgersen-Ntoumani, 2011; Gunnell et al., 2013) and it would seem logical to hypothesize that need thwarting would have a positive relationship with antisocial behavior in sport. Unfortunately we did not measure need thwarting in either of our studies; future research should assess these variables in relation to both antisocial and prosocial behavior.

Study 2 findings also indicated that perceived controlling coaches and teammates predicted higher levels of moral disengagement, whereas moral disengagement and controlling teammates led to higher levels of antisocial behaviour towards opponents and teammates (supporting $\mathrm{H} 2 \mathrm{f}$ and $\mathrm{H} 2 \mathrm{i}$ ). In Study 2 moral disengagement, coach and teammate climates, and need satisfaction explained an important amount of variance in antisocial 
behavior towards one's teammates $(42 \%)$ and opponents $(48 \%)$. These findings provided partial support for hypotheses $\mathrm{H} 2 \mathrm{f}, \mathrm{H} 2 \mathrm{~g}$ and $\mathrm{H} 2 \mathrm{~h}$. Moreover, moral disengagement partially mediated the relation between both controlling coach and teammate climates and antisocial behavior towards both teammates and opponents (study 2; supporting hypothesis $\mathrm{H} 2 \mathrm{i}$ ). These moral disengagement findings reflected evidence from a number of studies that have substantiated the relation between moral disengagement and antisocial behaviors in sport (Boardley \& Kavussanu, 2009; Boardley et al., 2014; Corrion et al., 2009; Kavussanu et al., 2013; Stanger et al., 2013). Athletes who perceive their coach and/or teammates as being high on controlling behaviors may have higher levels of moral disengagement because they will have increased exposure to coaching/teammate behaviors that promote compliance with authority (e.g., coercion, obedience, conditional regard), rather than an internalization and subsequent self-regulation of moral values. Bandura (2002) refers to such a process as 'gradualistic moral disengagement' which results in a decrease in self-regulation of moral action (cf. autonomy) and a potential increase in antisocial behaviors.

\section{Strengths, Limitations and Future Research}

We extended previous SDT research on antisocial and prosocial behavior in sport by (i) integrating basic psychological needs variables with prosocial and antisocial behaviors, (ii) integrating basic needs and moral disengagement, (iii) assessing controlling as well as autonomy-supportive climates, and (iv) assessing teammate as well as coach autonomysupportive and controlling climates. Analytically, we demonstrated the usefulness of Bayesian estimation for the integration of prior knowledge with new data. Nevertheless, like all research these studies were not without limitations. First, we relied on self-report, crosssectional data; consequently no causal relationships can be inferred from these findings. Second, both samples were from a young adult population, which limits the generalizability to other age groups. Third, some athletes were surveyed in their immediate off-season and 
they had to recall experiences from the previous season for their sport. Finally, we cannot rule out potential bias in the parameter estimates, owing to the assumption that variables are measured without error in path analysis and potential non-independence in the data (i.e., athletes nested within teams). Notwithstanding these limitations, our findings provide important insights into the moral and motivational underpinnings of antisocial and prosocial behaviors in sport. Future research should (i) employ longitudinal designs, (ii) assess direct behavioral observations of antisocial and prosocial behaviors, and (iii) experimentally examine the efficacy of interventions designed to increase autonomy-supportive motivational climates and basic need satisfaction (i.e., which, in turn, should decrease moral disengagement and antisocial behavior, and increase prosocial behavior). Finally, future research should also examine the issue of need thwarting instead of only measuring levels of need satisfaction. Recently, a number of authors have examined need thwarting in sport (e.g., Balaguer et al., 2012; Bartholomew, Ntoumanis, Ryan, Bosch, \& Thøgersen-Ntoumani, 2011; Gunnell et al., 2013), and a sport-specific need thwarting questionnaire has been developed (Bartholomew, Ntoumanis, Ryan, \& Thøgersen-Ntoumani, 2011). Nevertheless, this issue has yet to be investigated with respect to antisocial and prosocial behaviors in sport.

\section{Conclusion}

This two-study research project provided important insights into the moral and motivational underpinnings of antisocial and prosocial behaviors in sport. As hypothesized perceived coach and teammate autonomy-supportive climates had meaningful relations with need satisfaction and with prosocial behaviors. Furthermore, as hypothesized, perceived coach and teammate controlling climates had meaningful relations with antisocial behaviors. Need satisfaction revealed both direct and indirect relations with both prosocial and antisocial behaviors; while moral disengagement revealed direct and indirect relations with antisocial behaviors. Overall, these findings reflected substantial evidence from the SDT literature that 
autonomy-supportive versus controlling motivational climates are critical environmental influences for the satisfaction of the three basic needs; and that both autonomy-supportive coach and teammate climates, along with need satisfaction are important correlates of prosocial behavior in sport. Finally, controlling coach and teammate climates, along with moral disengagement, were important correlates of antisocial behavior in sport. 


\section{References}

Adie, J., Duda, J., \& Ntoumanis, N. (2012). Perceived coach-autonomy support, basic need satisfaction and the well- and ill-being of elite youth soccer players: A longitudinal investigation. Psychology of Sport \& Exercise, 13, 51-59.

doi:10.1016/j.psychsport.2011.07.008

Asparouhov, T., \& Muthén, B. (2010). Bayesian analysis using Mplus: Technical implementation. Retrieved from http://www.statmodel.com/download/Bayes3.pdf.

Baard, P., Deci, E., \& Ryan, R. (2004). Intrinsic need satisfaction: A motivational basis of performance and well-being in two work settings. Journal of Applied Social Psychology, 34, 2045-2068.

Balaguer, I., González, L., Fabra, P., Castillo, I., Mercé, J., \& Duda, J. (2012). Coaches' interpersonal style, basic psychological needs and the well- and ill-being of young soccer players: A longitudinal analysis. Journal of Sports Sciences, 30, 1619-1629. DOI: $10.1080 / 02640414.2012 .731517$

Bandura, A. (2002). Selective moral disengagement in the exercise of moral agency. Journal of Moral Education, 31, 101-119. DOI: 10.1080/0305724022014322

Bandura, A. (2006). Toward a psychology of human agency. Perspectives on Psychological Science, 1, 164-180. DOI: 10.1111/j.1745-6916.2006.00011.x

Barkoukis, V., Lazuras, L., Tsorbatzoudis, H., Rodafinos, A. (2011). Motivational and sportspersonship profiles of elite athletes in relation to doping behavior. Psychology of Sport \& Exercise, 12, 205-212. doi:10.1016/j.psychsport.2010.10.003

Bartholomew, K. J., Ntoumanis, N., \& Thøgersen-Ntoumani, C. (2010). The controlling interpersonal style in a coaching context: Development and initial validation of a psychometric scale. Journal of Sport \& Exercise Psychology, 32, 193-216. 
Bartholomew, K. J., Ntoumanis, N., Ryan, R. M., Bosch, J. A., \& Thøgersen-Ntoumani, C. (2011). Self-determination theory and diminished functioning: The role of interpersonal control and psychological need thwarting. Personality and Social Psychology Bulletin, 37, 1459-1503.

Bartholomew, K. J., Ntoumanis, N., Ryan, R. M., \& Thøgersen-Ntoumani, C. (2011). Psychological need thwarting in the sport context: Assessing the darker side of athletic experience. Journal of Sport \& Exercise Psychology, 33, 75-102.

Boardley, I., \& Kavussanu, M. (2008). The Moral Disengagement in Sport Scale - short. Journal of Sports Sciences, 26, 1507-1517. DOI: 10.1080/02640410802315054

Boardley, I., \& Kavussanu, M. (2009). The influence of social variables and moral disengagement on prosocial and antisocial behaviors in field hockey and netball. Journal of Sports Sciences, 27, 843-854. DOI: 10.1080/02640410902887283

Boardley, I., \& Kavussanu, M. (2011). Moral disengagement in sport. International Review of Sport \& Exercise Psychology, 4, 93-108.

Boardley, I., Grix, J., \& Dewar, A. (2014). Moral disengagement and associated processes in performance-enhancing drug use: A national qualitative investigation. Journal of Sports Sciences, 32, 836-844. doi: 10.1080/02640414.2013.862842

Corrion, K., Long, T., Smith, A., \& d'Arripe-Longueville, F. (2009). “It's not my fault; It's not serious": Athlete accounts of moral disengagement in competitive sport. The Sport Psychologist, 23, 388-404.

Deci, E., \& Ryan, R. (2000). The "what" and "why" of goal pursuits: Human needs and the self-determination of behavior. Psychological Inquiry, 11, 227-268.

Deci, E., \& Ryan, R. (Eds.), (2002). Handbook of self-determination research. Rochester, NY: University of Rochester Press. 
Eisenberg, N., \& Fabes, R. (1998). Prosocial development. In N. Eisenberg (Ed.), Handbook of child psychology. Vol 3: Social, emotional, and personality development (pp. 701778). New York: John Wiley.

Felton, L. \& Jowett, S. (2013). Attachment and well-being: The mediating effects of psychological need satisfaction within the coach-athlete and parent-athlete relational contexts. Psychology of Sport \& Exercise, 14, 57-65. doi.org/10.1016/j.psychsport.2012.07.006

Gagné, M. (2003). The role of autonomy support and autonomy orientation in prosocial behavior engagement. Motivation and Emotion, 27, 199-223.

Gagné, M., Ryan, R., \& Bargmann, K. (2003). Autonomy support and need satisfaction in the motivation and well-being of gymnasts. Journal of Applied Sport Psychology, 15, 372-390.

Gelman, A., Meng, X.-L., \& Stern, H. (1996). Posterior predictive assessment of model fitness via realized discrepancies. Statistica Sinica, 6, 733-759.

Gucciardi, D., \& Jackson, B. (2015). Understanding sport continuation: An integration of the theories of planned behavior and basic psychological needs. Journal of Science \& Medicine in Sport, 18, 31-36. doi: 10.1016/j.jsams.2013.11.011

Gunnell, K., Crocker, P., Wilson, P., Mack, D., \& Zumbo, B. (2013). Psychological need satisfaction and thwarting: A test of basic psychological needs theory in physical activity contexts. Psychology of Sport \& Exercise, 14, 599-607. doi.org/10.1016/j.psychsport.2013.03.007

Hodge, K., \& Lonsdale, C. (2011). Prosocial and antisocial behavior in sport: The role of coaching style, autonomous vs. controlled motivation, and moral disengagement. Journal of Sport \& Exercise Psychology, 33, 527-547. 
Hodge, K., Hargreaves, E., Gerrard, D., \& Lonsdale, C. (2013). Psychological mechanisms underlying doping attitudes in sport: Motivation and moral disengagement. Journal of Sport \& Exercise Psychology, 35, 419-432.

Jõesaar, H., Hein, V., \& Hagger, M. (2011). Peer influence on young athletes’ need satisfaction, intrinsic motivation and persistence in sport: A 12-month prospective study. Psychology of Sport \& Exercise, 12, 500-508. doi:

10.1016/j.psychsport.2011.04.005

Kavussanu, M., \& Boardley, I. (2009). The Prosocial and Antisocial Behavior in Sport Scale. Journal of Sport \& Exercise Psychology, 31, 97-117.

Kavussanu, M., Stanger, N., \& Boardley, I. (2013) The Prosocial and Antisocial Behavior in Sport Scale: Further evidence for construct validity and reliability. Journal of Sports Sciences, 31, 1208-1221. doi:10.1080/02640414.2013.775473

Kipp, L., \& Weiss, M. (2013). Social influences, psychological need satisfaction, and wellbeing among female adolescent gymnasts. Sport, Exercise, \& Performance Psychology, 2, 62-75. doi: 10.1037/a0030236

Li, C., Wang, C. K., Pyun, D. Y., \& Kee, Y. H. (2013). Burnout and its relations with basic psychological needs and motivation among athletes: A systematic review and metaanalysis. Psychology of Sport \& Exercise, 14, 692-700. doi:10.1016/j.psychsport.2013.04.009

Long, T., Pantaléon, N., Bruant, G., \& d'Arripe-Longueville, F. (2006). A qualitative study of moral reasoning of young elite athletes. The Sport Psychologist, 20, 330-347.

McDavid, L., Cox. A., \& McDonough, M. (2014). Need fulfillment and motivation in physical education predict trajectories of change in leisure-time physical activity in early adolescence. Psychology of Sport \& Exercise, 15, 471-480. 
Mahoney, J.W., Gucciardi, D.F., Ntoumanis, N., \& Mallett, C.J. (2014). Mental toughness in sport: Motivational antecedents and associations with performance and health. Journal of Sport \& Exercise Psychology, 36, 281-292.

Molix, L. \& Nichols, C. (2013). Satisfaction of basic psychological needs as a mediator of the relationship between community esteem and wellbeing. International Journal of Wellbeing, 3, 20-34. doi:10.5502/ijw.v3i1.2

Moreau, E., \& Mageau, G. (2012). The importance of perceived autonomy support for the psychological health and work satisfaction of health professionals: Not only supervisors count, colleagues too! Motivation \& Emotion, 36, 268-286. DOI $10.1007 / \mathrm{s} 11031-011-9250-9$

Muthén, B. O., \& Asparouhov, T. (2012). Bayesian structural equation modeling: A more flexible representation of substantive theory. Psychological Methods, 17, 313-335. doi: $10.1037 / \mathrm{a} 0026802$

Muthén, L. K., \& Muthén, B. O. (1998-2012). Mplus user's guide (7th ed.). Los Angeles, CA: Muthén \& Muthén.

Ng, J., Lonsdale, C., \& Hodge, K. (2011). The Basic Need Satisfaction in Sport Scale (BNSSS): Instrument development and initial validity evidence. Psychology of Sport \& Exercise, 12, 257-264. doi:10.1016/j.psychsport.2010.10.006

Ntoumanis, N., \& Standage, M. (2009). Morality in sport: A self-determination theory perspective. Journal of Applied Sport Psychology, 21, 365-380.

Ntoumanis, N., Taylor, I. M., \& Thøgersen-Ntoumani, C. (2012). A longitudinal examination of coach \& peer motivational climates in youth sport: Implications for moral attitudes, well-being, \& behavioral investment. Developmental Psychology, 48, 213-223.

Nunnally, J. C., \& Bernstein, I. H. (1994). Psychometric theory (3rd ed.). New York: McGraw-Hill. 
Pavey, L., Greitemeyer, Y., \& Sparks, P. (2011). Highlighting relatedness promotes prosocial motives and behavior. Personality \& Social Psychology Bulletin, 37, 905-917.

Ryan, R., \& Deci, E. (2000). Self-determination theory and the facilitation of intrinsic motivation, social development, and well-being. American Psychologist, 55, 68-78.

Rutten, E., Schuengel, C., Dirks, E., Stams, G., Biesta, G., \& Hoeksma, J. (2011). Predictors of antisocial and prosocial behavior in an adolescent sports context. Social Development, 20, 294-315. doi: 10.1111/j.1467-9507.2010.00598.x

Sheldon, K., Zhaoyang, R., \& Williams, M. (2013). Psychological need-satisfaction and basketball performance. Psychology of Sport \& Exercise, 14, 675-681.

Stanger, N., Kavussanu, M., Boardley, I., \& Ring, C. (2013). The influence of moral disengagement and negative emotion on antisocial sport behavior. Sport, Exercise, \& Performance Psychology, 2, 117-129. doi: 10.1037/a0030585

Steffens, L. (1904/1957). The Shame of the Cities. New York, NY: Sagamore Press.

van de Schoot, R., Kaplan, D., Denissen, J., Asendorpf, J. B., Neyer, F. J., \& van Aken, A. G. (2014). A gentle introduction to Bayesian analysis: Applications to developmental research. Child Development, 85, 842-860. doi: 10.1111/cdev.12169

Weinstein, N., \& Ryan, R. M. (2010). When helping helps: Autonomous motivation for prosocial behavior and its influence on well-being for the helper and the recipient. Journal of Personality and Social Psychology, 98, 222-244.

Williams, G., Cox, E., Kouides, R., \& Deci, E. (1999). Presenting the facts about smoking to adolescents: The effects of an autonomy-supportive style. Archives of Pediatrics \& Adolescent Medicine, 153, 959-964.

Yuan, Y., \& MacKinnon, D. P. (2009). Bayesian mediation analysis. Psychological Methods, 14, 301-322. doi: 10.1037/a0016972 
Zyphur, M. J., \& Oswald, F. L. (2015). Bayesian estimation and inference: A user's guide. Journal of Management, 41, 390-420. doi: 10.1177/0149206313501200 


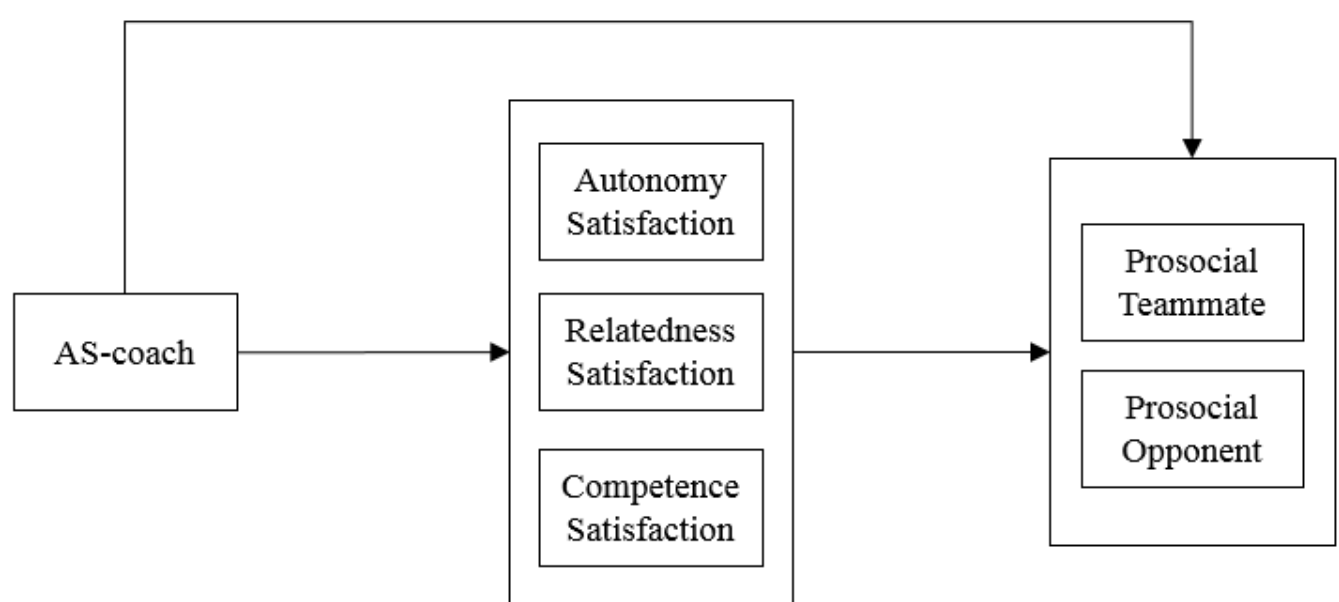

Figure 1. Theoretical model tested in Study 1. Note: covariances among the three basic psychological needs, and between the two prosocial behaviors are not shown; AS-coach $=$ coach autonomy support.

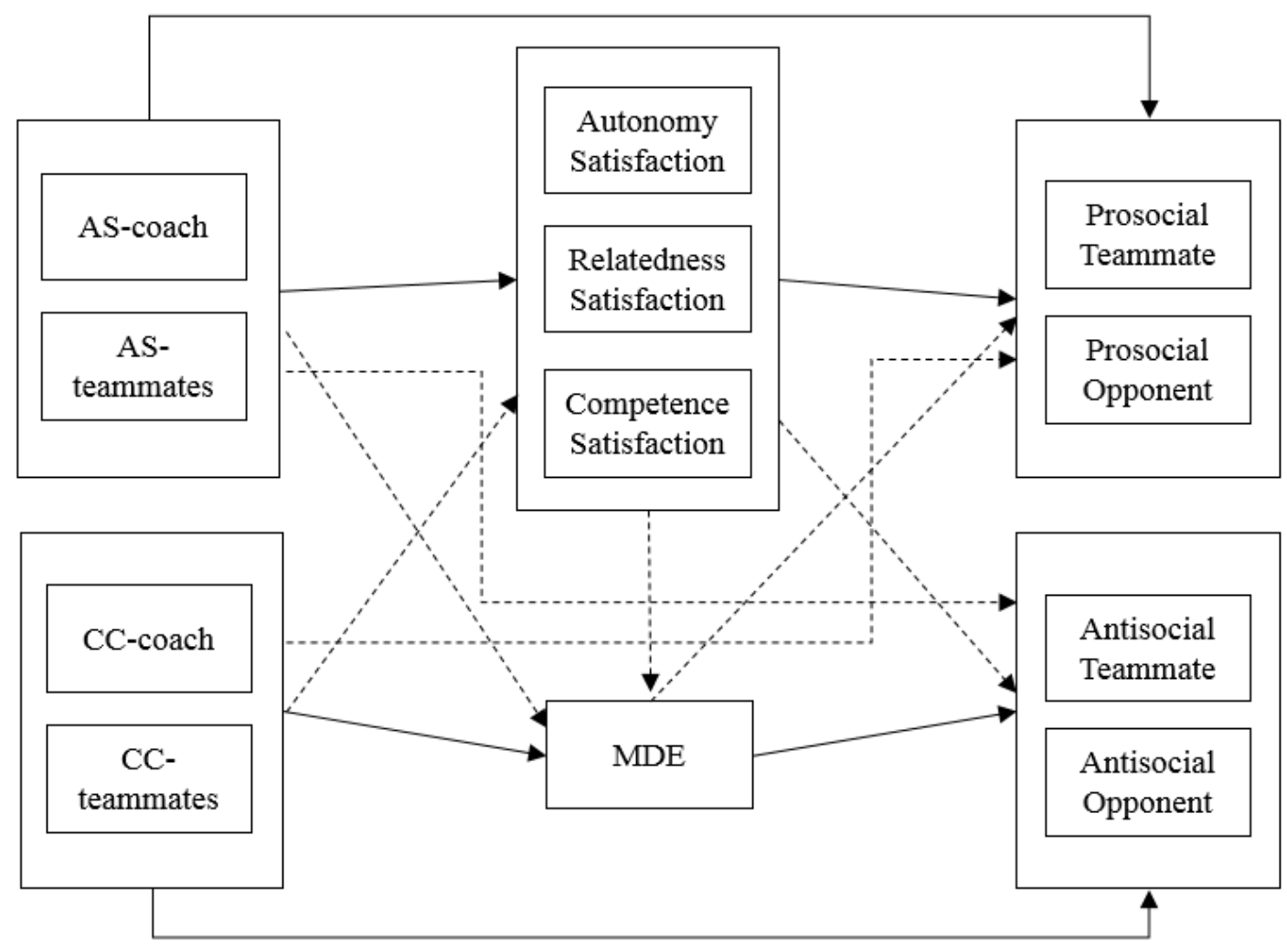

Figure 2. Theoretical model tested in Study 2. Note: covariances among endogenous and exogenous variables are not shown; solid line = hypothesized positive relation, dotted line = hypothesized inverse relation. AS-coach/teammate = coach/teammate autonomy support; CCcoach/teammate $=$ coach/teammate controlling climate $; \mathrm{MDE}=$ moral disengagement 
Table 1. Overview of priors employed in Bayesian path analysis.

\begin{tabular}{|c|c|c|c|c|c|c|c|c|}
\hline & \multicolumn{4}{|c|}{ Study 1} & \multicolumn{4}{|c|}{ Study 2} \\
\hline & $\mathrm{M}$ & $\sigma^{2}$ & Form & Prior Type & $\mathrm{M}$ & $\sigma^{2}$ & Form & Prior Type \\
\hline AS-coach $\rightarrow$ Rel & .40 & .02 & Normal & $E$ & .297 & .005 & Normal & $\mathrm{E}$ \\
\hline AS-coach $\rightarrow$ Com & .20 & .02 & Normal & $\mathrm{E}$ & .237 & .005 & Normal & $\mathrm{E}$ \\
\hline AS-coach $\rightarrow$ Aut & .35 & .02 & Normal & $\mathrm{E}$ & .342 & .004 & Normal & $\mathrm{E}$ \\
\hline Rel $\rightarrow$ Pro-tm & .40 & .04 & Normal & $\mathrm{T}$ & .198 & .005 & Normal & $\mathrm{E}$ \\
\hline Com $\rightarrow$ Pro-tm & .40 & .04 & Normal & $\mathrm{T}$ & .143 & .01 & Normal & $\mathrm{E}$ \\
\hline Aut $\rightarrow$ Pro-tm & .40 & .04 & Normal & $\mathrm{T}$ & .074 & .01 & Normal & $\mathrm{E}$ \\
\hline AS-coach $\rightarrow$ Pro-tm & .20 & .02 & Normal & $\mathrm{E}$ & -.041 & .01 & Normal & $\mathrm{E}$ \\
\hline $\mathrm{Rel} \rightarrow$ Pro-opp & .40 & .04 & Normal & $\mathrm{T}$ & .124 & .02 & Normal & $\mathrm{E}$ \\
\hline Com $\rightarrow$ Pro-opp & .40 & .04 & Normal & $\mathrm{T}$ & .139 & .02 & Normal & $\mathrm{E}$ \\
\hline Aut $\rightarrow$ Pro-opp & .40 & .04 & Normal & $\mathrm{E}$ & .004 & .0005 & Normal & $\mathrm{E}$ \\
\hline AS-coach $\rightarrow$ Pro-opp & .05 & .02 & Normal & $\mathrm{T}$ & -.047 & .01 & Normal & $\mathrm{E}$ \\
\hline AS-teammate $\rightarrow$ Rel & & & & & .40 & .04 & Normal & $\mathrm{T}$ \\
\hline AS-teammate $\rightarrow$ Com & & & & & .40 & .04 & Normal & $\mathrm{T}$ \\
\hline AS-teammate $\rightarrow$ Aut & & & & & .40 & .04 & Normal & $\mathrm{T}$ \\
\hline Rel $\rightarrow$ Anti-tm & & & & & -.40 & .04 & Normal & $\mathrm{T}$ \\
\hline Com $\rightarrow$ Anti-tm & & & & & -.40 & .04 & Normal & $\mathrm{T}$ \\
\hline Aut $\rightarrow$ Anti-tm & & & & & -.40 & .04 & Normal & $\mathrm{T}$ \\
\hline AS-teammate $\rightarrow$ Anti-tm & & & & & -.40 & .04 & Normal & $\mathrm{T}$ \\
\hline Rel $\rightarrow$ Anti-opp & & & & & -.40 & .04 & Normal & $\mathrm{T}$ \\
\hline Com $\rightarrow$ Anti-opp & & & & & -.40 & .04 & Normal & $\mathrm{T}$ \\
\hline Aut $\rightarrow$ Anti-opp & & & & & -.40 & .04 & Normal & $\mathrm{T}$ \\
\hline AS-teammate $\rightarrow$ Anti-opp & & & & & -.40 & .04 & Normal & $\mathrm{T}$ \\
\hline Control-coach $\rightarrow$ Rel & & & & & 0 & .02 & Normal & $\mathrm{E}$ \\
\hline Control-coach $\rightarrow$ Com & & & & & 0 & .02 & Normal & $\mathrm{E}$ \\
\hline Control-coach $\rightarrow$ Aut & & & & & 0 & .02 & Normal & $\mathrm{E}$ \\
\hline Control-teammate $\rightarrow$ Rel & & & & & 0 & .02 & Normal & $\mathrm{E}$ \\
\hline Control-teammate $\rightarrow$ Com & & & & & 0 & .02 & Normal & $\mathrm{E}$ \\
\hline Control-teammate $\rightarrow$ Aut & & & & & 0 & .02 & Normal & $\mathrm{E}$ \\
\hline Control-coach $\rightarrow$ MDE & & & & & .40 & .04 & Normal & $\mathrm{T}$ \\
\hline Control-teammate $\rightarrow$ MDE & & & & & .40 & .04 & Normal & $\mathrm{T}$ \\
\hline AS-coach $\rightarrow$ MDE & & & & & -.40 & .04 & Normal & $\mathrm{T}$ \\
\hline AS-teammate $\rightarrow$ MDE & & & & & -.40 & .04 & Normal & $\mathrm{T}$ \\
\hline $\mathrm{Rel} \rightarrow \mathrm{MDE}$ & & & & & -.40 & .04 & Normal & $\mathrm{T}$ \\
\hline $\mathrm{Com} \rightarrow \mathrm{MDE}$ & & & & & -.40 & .04 & Normal & $\mathrm{T}$ \\
\hline Aut $\rightarrow \mathrm{MDE}$ & & & & & -.40 & .04 & Normal & $\mathrm{T}$ \\
\hline $\mathrm{MDE} \rightarrow$ Anti-tm & & & & & .40 & .04 & Normal & $\mathrm{T}$ \\
\hline MDE $\rightarrow$ Anti-opp & & & & & .40 & .04 & Normal & $\mathrm{T}$ \\
\hline $\mathrm{MDE} \rightarrow$ Pro-tm & & & & & -.40 & .04 & Normal & $\mathrm{T}$ \\
\hline $\mathrm{MDE} \rightarrow$ Pro-opp & & & & & -.40 & .04 & Normal & $\mathrm{T}$ \\
\hline Control-coach $\rightarrow$ Anti-tm & & & & & .40 & .04 & Normal & $\mathrm{T}$ \\
\hline Control-teammate $\rightarrow$ Anti-tm & & & & & .40 & .04 & Normal & $\mathrm{T}$ \\
\hline Control-coach $\rightarrow$ Anti-opp & & & & & .40 & .04 & Normal & $\mathrm{T}$ \\
\hline Control-teammate $\rightarrow$ Anti-opp & & & & & .40 & .04 & Normal & $\mathrm{T}$ \\
\hline Control-coach $\rightarrow$ Pro-tm & & & & & -.40 & .04 & Normal & $\mathrm{T}$ \\
\hline Control-teammate $\rightarrow$ Pro-tm & & & & & -.40 & .04 & Normal & $\mathrm{T}$ \\
\hline Control-coach $\rightarrow$ Pro-opp & & & & & -.40 & .04 & Normal & $\mathrm{T}$ \\
\hline Control-teammate $\rightarrow$ Pro-opp & & & & & -.40 & .04 & Normal & $\mathrm{T}$ \\
\hline Residual variances & .001 & .001 & $\mathrm{IG}$ & $\mathrm{D}$ & .001 & .001 & $\mathrm{IG}$ & $\mathrm{D}$ \\
\hline Covariance matrix & 0 & $10^{10}$ & Normal & $\mathrm{D}$ & 0 & $10^{10}$ & Normal & $\mathrm{D}$ \\
\hline
\end{tabular}

Note: $\mu=$ mean; $\sigma^{2}=$ variance; Form = distributional form of the prior; $\mathrm{IG}=$ Inverse Gamma; $\mathrm{E}=$ empirically-informed prior; $\mathrm{T}=$ theoretically-informed prior; $\mathrm{D}=$ default prior; AS-coach $=$ coach autonomy support; AS-teammate = teammate autonomy support; Controlcoach = controlling coach climate; Control-teammate = controlling teammate climate; Pro-tm = prosocial behavior toward teammates; Proopp = prosocial behavior toward opponents; Anti-tm = antisocial behavior toward teammates; Anti-opp = antisocial behavior toward opponents; Rel = satisfaction of relatedness; Com = satisfaction of competence; Aut = satisfaction of autonomy; MDE = moral disengagement. 
Table 2. Descriptive statistics, internal reliability estimates, and zero-order correlations among the variables in Study 1 (Note: AS-coach = coach autonomy support; Prosocial-tm = prosocial behavior toward teammates; Prosocial-opp = prosocial behavior toward opponents; ${ }^{*} p$ $\left.<.05,{ }^{\#} p<.01\right)$.

\begin{tabular}{llcccccccc}
\hline & & $\mathrm{M}$ & $\mathrm{SD}$ & 1 & 2 & 3 & 4 & 5 & 6 \\
\hline 1 & AS-coach & 4.95 & 1.18 & $(.95)$ & $.55^{\#}$ & $.40^{\#}$ & $.36^{\#}$ & $.14^{*}$ & .01 \\
2 & Autonomy & 5.65 & .73 & & $(.82)$ & $.42^{\#}$ & $.54^{\#}$ & $.25^{\#}$ & .03 \\
3 & Relatedness & 5.57 & .86 & & & $(.81)$ & $.38^{\#}$ & $.36^{\#}$ & .11 \\
4 & Competence & 5.74 & .78 & & & & $(.79)$ & $.31^{\#}$ & .11 \\
5 & Prosocial-tm & 4.30 & .58 & & & & & $(.82)$ & $.27^{*}$ \\
6 & Prosocial-opp & 3.19 & .93 & & & & & & $(.76)$ \\
\hline
\end{tabular}

Table 3. Descriptive statistics, internal reliability estimates, and zero-order correlations among the variables in Study 2 (Note: AS-coach = coach autonomy support; AS-teammate = teammate autonomy support; MDE = moral disengagement; Prosocial-tm = prosocial behavior toward teammates; Prosocial-opp = prosocial behavior toward opponents; Antisocial-tm = antisocial behavior toward teammates; Antisocialopp = antisocial behavior toward opponents; $\left.{ }^{*} p<.05,{ }^{*} p<.01\right)$.

\begin{tabular}{|c|c|c|c|c|c|c|c|c|c|c|c|c|c|c|c|}
\hline & & $\mathrm{M}$ & SD & 1 & 2 & 3 & 4 & 5 & 6 & 7 & 8 & 9 & 10 & 11 & 12 \\
\hline 1 & AS-coach & 5.15 & 1.07 & $(.95)$ & $.43^{\#}$ & $-.39^{\#}$ & $-.18^{\#}$ & $.43^{\#}$ & $.44^{\#}$ & $.31^{\#}$ & -.09 & $.25^{\#}$ & .11 & $-.12 *$ & $-.15^{*}$ \\
\hline 2 & AS-teammate & 5.34 & .90 & & $(.93)$ & $-.12 *$ & $-.19^{\#}$ & $.39^{\#}$ & $.57^{\#}$ & $.25^{\#}$ & -.08 & $.35^{\#}$ & $.17^{\#}$ & $-.19^{\#}$ & -.12 \\
\hline 3 & Control-coach & 2.60 & 1.08 & & & $(.91)$ & $.67^{\#}$ & $-.23^{\#}$ & $-.15^{*}$ & -.06 & $.32^{\#}$ & $-.13 *$ & .04 & $.37^{\#}$ & $.34^{\#}$ \\
\hline 4 & Control-teammate & 2.22 & 1.03 & & & & $(.93)$ & $-.20^{\#}$ & $-.13 *$ & -.02 & $.31^{\#}$ & -.10 & .01 & $.43^{\#}$ & $.35^{\#}$ \\
\hline 5 & Autonomy & 5.75 & .69 & & & & & $(.82)$ & $.49^{\#}$ & $.61^{\#}$ & -.07 & $.33^{\#}$ & $.15^{*}$ & -.08 & -.08 \\
\hline 6 & Relatedness & 5.79 & .82 & & & & & & $(.81)$ & $.43^{\#}$ & -.07 & $.45^{\#}$ & $.26^{\#}$ & -.08 & -.10 \\
\hline 7 & Competence & 5.78 & .76 & & & & & & & $(.80)$ & .04 & $.33^{\#}$ & .10 & .05 & -.02 \\
\hline 8 & MDE & 2.50 & 1.19 & & & & & & & & $(.87)$ & -.06 & $-.14 *$ & $.56^{\#}$ & $.65^{\#}$ \\
\hline 9 & Prosocial-tm & 4.38 & .51 & & & & & & & & & $(.74)$ & $.35^{\#}$ & .03 & .02 \\
\hline 10 & Prosocial-opp & 3.48 & .95 & & & & & & & & & & $(.78)$ & -.11 & -.02 \\
\hline 11 & Antisocial-tm & 2.02 & .79 & & & & & & & & & & & $(.86)$ & $.65^{\#}$ \\
\hline 12 & Antisocial-opp & 2.03 & .87 & & & & & & & & & & & & $(.91)$ \\
\hline
\end{tabular}


Table 4. Summary of standardized direct effects tested in Studies 1 and 2.

\begin{tabular}{|c|c|c|c|c|}
\hline & \multicolumn{2}{|c|}{ Study 1} & \multicolumn{2}{|c|}{ Study 2} \\
\hline & MLR & Bayesian & MLR & Bayesian \\
\hline & $\beta(95 \% \mathrm{CI})$ & $\beta(95 \% \mathrm{CrI})$ & $\beta(95 \% \mathrm{CI})$ & $\beta(95 \% \mathrm{CrI})$ \\
\hline AS-coach $\rightarrow$ Rel & $.40(.29, .51)$ & $.41(.31, .49)$ & $.23(.10, .36)$ & $.28(.19, .37)$ \\
\hline AS-coach $\rightarrow$ Com & $.36(.24, .49)$ & $.36(.26, .46)$ & $.22(.08, .36)$ & $.31(.21, .41)$ \\
\hline AS-coach $\rightarrow$ Aut & $.56(.47, .65)$ & $.55(.48, .63)$ & $.33(.19, .46)$ & $.36(.26, .45)$ \\
\hline Rel $\rightarrow$ Pro-tm & $.29(.18, .41)$ & $.29(.18, .40)$ & $.22(.06, .38)$ & $.27(.15, .38)$ \\
\hline Com $\rightarrow$ Pro-tm & $.19(.06, .32)$ & $.19(.07, .31)$ & $.20(.07, .34)$ & $.16(.04, .28)$ \\
\hline Aut $\rightarrow$ Pro-tm & $.07(-.09, .23)$ & $.09(-.04, .23)$ & $.03(-.11, .16)$ & $.03(-.09, .16)$ \\
\hline AS-coach $\rightarrow$ Pro-tm & $-.09(-.20, .02)$ & $-.08(-.21, .04)$ & $-.07(-.20, .06)$ & $-.05(-.18, .07)$ \\
\hline Rel $\rightarrow$ Pro-opp & $.10(-.03, .24)$ & $.11(-.01, .24)$ & $.21(.07, .36)$ & $.18(.05, .30)$ \\
\hline Com $\rightarrow$ Pro-opp & $.11(-.03, .25)$ & $.12(-.01, .24)$ & $.11(-.04, .26)$ & $.04(-.08, .15)$ \\
\hline Aut $\rightarrow$ Pro-opp & $-.05(-.23, .13)$ & $.00(-.13, .13)$ & $.00(-.15, .15)$ & $.00(-.03, .03)$ \\
\hline AS-coach $\rightarrow$ Pro-opp & $-.04(-.18, .09)$ & $-.06(-.19, .07)$ & $-.03(-.19, .14)$ & $-.01(-.13, .10)$ \\
\hline AS-teammate $\rightarrow$ Rel & & & $.46(.34, .59)$ & $.45(.35, .54)$ \\
\hline AS-teammate $\rightarrow$ Com & & & $.22(.07, .38)$ & $.15(.03, .26)$ \\
\hline AS-teammate $\rightarrow$ Aut & & & $.21(.08, .34)$ & $.23(.12, .33)$ \\
\hline Rel $\rightarrow$ Anti-tm & & & $.04(-.10, .18)$ & $.03(-.09, .15)$ \\
\hline Com $\rightarrow$ Anti-tm & & & $.08(-.04, .21)$ & $.02(-.09, .13)$ \\
\hline Aut $\rightarrow$ Anti-tm & & & $.03(-.10, .16)$ & $.01(-.11, .13)$ \\
\hline AS-coach $\rightarrow$ Anti-tm & & & $.00(-.11, .11)$ & $.02(-.10, .13)$ \\
\hline AS-teammate $\rightarrow$ Anti-tm & & & $-.17(-.30,-.04)$ & $-.15(-.26,-.04)$ \\
\hline Rel $\rightarrow$ Anti-opp & & & $.00(-.11, .12)$ & $-.02(-.13, .09)$ \\
\hline $\mathrm{Com} \rightarrow$ Anti-opp & & & $-.03(-.13, .07)$ & $-.06(-.17, .04)$ \\
\hline Aut $\rightarrow$ Anti-opp & & & $.08(-.03, .18)$ & $.05(-.07, .16)$ \\
\hline AS-coach $\rightarrow$ Anti-opp & & & $-.07(-.17, .04)$ & $-.05(-.16, .06)$ \\
\hline AS-teammate $\rightarrow$ Anti-opp & & & $-.03(-.14, .08)$ & $-.03(-.13, .08)$ \\
\hline Control-coach $\rightarrow$ Rel & & & $-.07(-.26, .12)$ & $.01(-.12, .13)$ \\
\hline Control-coach $\rightarrow$ Com & & & $.07(-.08, .23)$ & $.06(-.08, .20)$ \\
\hline Control-coach $\rightarrow$ Aut & & & $.03(-.14, .20)$ & $.01(-.12, .14)$ \\
\hline Control-teammate $\rightarrow$ Rel & & & $.08(-.09, .25)$ & $.01(-.11, .12)$ \\
\hline Control-teammate $\rightarrow$ Com & & & $.05(-.11, .20)$ & $.03(-.11, .16)$ \\
\hline Control-teammate $\rightarrow$ Aut & & & $-.13(-.28, .03)$ & $-.09(-.22, .04)$ \\
\hline Control-coach $\rightarrow$ MDE & & & $.19(.00, .38)$ & $.20(.05, .33)$ \\
\hline Control-teammate $\rightarrow \mathrm{MDE}$ & & & $.16(-.03, .34)$ & $.18(.04, .31)$ \\
\hline AS-coach $\rightarrow$ MDE & & & $.04(-.12, .21)$ & $.02(-.11, .14)$ \\
\hline AS-teammate $\rightarrow$ MDE & & & $.00(-.15, .15)$ & $-.04(-.16, .09)$ \\
\hline $\mathrm{Rel} \rightarrow \mathrm{MDE}$ & & & $.01(-.13, .16)$ & $-.04(-.17, .09)$ \\
\hline $\mathrm{Com} \rightarrow \mathrm{MDE}$ & & & $.12(.00, .25)$ & $.04(-.08, .16)$ \\
\hline Aut $\rightarrow$ MDE & & & $-.11(-.27, .04)$ & $-.04(-.16, .09)$ \\
\hline $\mathrm{MDE} \rightarrow$ Anti-tm & & & $.45(.35, .55)$ & $.45(.36, .54)$ \\
\hline $\mathrm{MDE} \rightarrow$ Anti-opp & & & $.61(.50, .71)$ & $.58(.50, .66)$ \\
\hline $\mathrm{MDE} \rightarrow$ Pro-tm & & & $-.05(-.15, .06)$ & $-.03(-.14, .08)$ \\
\hline $\mathrm{MDE} \rightarrow$ Pro-opp & & & $-.18(-.31,-.06)$ & $-.17(-.29,-.05)$ \\
\hline Control-coach $\rightarrow$ Anti-tm & & & $.09(-.04, .22)$ & $.10(-.03, .23)$ \\
\hline Control-teammate $\rightarrow$ Anti-tm & & & $.20(.07, .34)$ & $.21(.09, .33)$ \\
\hline Control-coach $\rightarrow$ Anti-opp & & & $.05(-.10, .19)$ & $.05(-.07, .17)$ \\
\hline Control-teammate $\rightarrow$ Anti-opp & & & $.14(.01, .28)$ & $.13(.02, .25)$ \\
\hline Control-coach $\rightarrow$ Pro-tm & & & $-.06(-.21, .11)$ & $-.09(-.23, .06)$ \\
\hline Control-teammate $\rightarrow$ Pro-tm & & & $.03(-.10, .16)$ & $.02(-.12, .16)$ \\
\hline Control-coach $\rightarrow$ Pro-opp & & & $.14(-.03, .32)$ & $.08(-.07, .23)$ \\
\hline Control-teammate $\rightarrow$ Pro-opp & & & $.03(-.13, .19)$ & $.01(-.14, .15)$ \\
\hline
\end{tabular}

(Note: gray shading represents $95 \%$ intervals that do not encompass zero; $\mathrm{CrI}=$ credibility interval; $\mathrm{CI}=\mathrm{confidence}$ interval; $\mathrm{AS}$-coach $=$ coach autonomy support; AS-teammate = teammate autonomy support; Control-coach $=$ controlling coach climate; Control-teammate = controlling teammate climate; Pro-tm = prosocial behavior toward teammates; Pro-opp = prosocial behavior toward opponents; Anti-tm = antisocial behavior toward teammates; Anti-opp = antisocial behavior toward opponents; Rel = satisfaction of relatedness; Com = satisfaction of competence; Aut = satisfaction of autonomy; $\mathrm{MDE}=$ moral disengagement $)$. 